\title{
Vaginosis bacteriana, comportamiento sexual, higiene genital y estrés en embarazadas: estudio de casos y controles (Medellín, Colombia)
}

\author{
Bacterial vaginosis, sexual behavior, genital hygiene, and stress in \\ pregnant women: a case-control study (Medellin, Colombia)
}

Lucia S. Tamayo Acevedo PhD', Edwin C. Guevara Romero $\mathrm{MSC}^{2}$, Liliana P. Álvarez Osorio $\mathrm{MB}^{3}$

Introducción: la vaginosis bacteriana es una infección frecuente, de etiología desconocida, que involucra cambios en el microambiente vaginal y favorece durante el embarazo las infecciones ascendentes en el canal vaginal, el útero $y$ anexos, acarreando complicaciones como el parto prematuro. Objetivo: establecer la asociación de la vaginosis bacteriana con factores socioeconómicos, prácticas sexuales, higiene genital y estrés psicológico en embarazadas menores de 26 años (Medellín, Colombia). Materiales y métodos: se estudiaron 90 casos y 217 controles. Se tuvieron en cuenta la presencia de tres de cinco criterios de Amsel para el diagnóstico de vaginosis bacteriana. Resultados: el 51,7\% de los casos estaban en el segundo trimestre del embarazo y el 57,7\% de controles en el tercero. La distribución de las variables de estudio fue similar entre ambos grupos. La vaginosis bacteriana se asoció inversamente con la candidiasis (razón de disparidad: 10,9; intervalo de confianza del 95\%: 3,1-38,5), el segundo trimestre del embarazo (razón de disparidad: 0,51; intervalo de confianza del 95\%: 0,30-

\footnotetext{
${ }^{1}$ Enfermera, Especialista en Estudios Internacionales, MSc en Epidemiología, PhD en Ciencias Médicas. Docente, Escuela de Microbiología, Universidad de Antioquia. Medellín, Colombia. Correspondencia: Dirección: Calle 67 \# 53-108, Escuela de Microbiología, Universidad de Antioquia. Teléfono: 5742195488. Correo electrónico: lucia.tamayo@udea.edu.co

2 Microbiólogo y Bioanalista, Msc en Epidemiología. Epidemiólogo, Secretaría de Salud y Bienestar de Medellín. Medellín, Colombia.

${ }^{3}$ Microbióloga y Bioanalista, Universidad de Antioquia. Medellín, Colombia.

Conflicto de intereses: los autores declaran que no tienen conflictos de intereses

Medicina \& Laboratorio 2016; 22: 71-86

Módulo 19 (Investigación), número 43. Editora Médica Colombiana S.A. $2016^{\circ}$

Recibido el 10 de enero de 2016; aceptado el 02 de febrero de 2016
} 
0,85), el inicio de las relaciones sexuales antes de los 15 años (razón de disparidad: 0,83; intervalo de confianza del 95\%: 0,70-0,97) y, después de ajustar por edad, al estrés y la tricomoniasis. El nivel de estrés fue mayor en los controles. Conclusiones: la vaginosis bacteriana se asoció con la ausencia de candidiasis, el segundo trimestre del embarazo y el inicio de las relaciones sexuales antes de los 15 años, pero no con las demás variables en estudio, lo que evidencia la discrepancia con las asociaciones reportadas en la literatura.

Palabras clave: vaginosis bacteriana, embarazo, factores de riesgo, estrés psicológico, conducta sexual, higiene genital, adolescente.

Introduction: Bacterial vaginosis is a frequent infection of unknown etiology involving changes in the vaginal microenvironment that favors ascending infections in the vaginal canal, uterus, and annexes in pregnancy, leading to complications such as preterm birth. Objective: To establish the association of bacterial vaginosis with socio-economic factors, sexual practices, genital hygiene and stress in pregnant less than 26 years of Medellin, Colombia. Materials and methods: 90 cases and 217 controls were studied. Three of five criteria proposed by Amsel were considered for bacterial vaginosis diagnosis. Results: $51.7 \%$ of cases were in the second trimester of pregnancy and $57.7 \%$ of controls in the third one. The distribution of variables of the study was similar in both groups. Bacterial vaginosis was inversely associated with candidiasis (odds ratio: 10.9; 95\% confidence interval: 3.1-38.5), second trimester of pregnancy (odds ratio: $0.51 ; 95 \%$ confidence interval: $0.30-0.85$ ), onset of sexual intercourse before age 15 (odds ratio: $0.83 ; 95 \%$ confidence interval: 0.70-0.97), and after adjusting for age, with stress and trichomoniasis. The stress level was higher in controls. Conclusions: Bacterial vaginosis was associated with the absence of candidiasis, the second trimester of pregnancy and the start of sexual relationships before 15 years old, most not with the others variables in the study, showing the discrepancy with previously associations reported in the literature.

Key words: Bacterial vaginosis, pregnancy, risk factors, psychological stress, sexual behavior, genital hygiene, adolescent.

Tamayo-Acevedo LS, Guevara-Romero EC, Álvarez-Osorio LP. Vaginosis bacteriana, comportamiento sexual, higiene genital y estrés en embarazadas: estudio de casos y controles (Medellín, Colombia). Medicina \& Laboratorio 2016; 22: 71-86.

$\mathrm{L}$ a vaginosis bacteriana, denominada vaginitis inespecífica, vaginitis anaeróbica y vaginitis por Haemophilus vaginalis, es un síndrome de etiología desconocida que involucra cambios en el microambiente vaginal. En esta condición los lactobacilos, parte de la microbiota normal, son reemplazados parcial o totalmente por una mezcla de microbiota anaeróbica predominante, compuesta por el complejo GAMM: Gardnerella vaginalis, anaerobios (géneros Bacteroides, 
Peptococcus y Peptoestreptococcus y miembros de la familia Enterobacteriaceae), Mycoplasma (hominis; y Ureaplasma urealyticum) y Mobiluncus spp. [1-4]. En algunos casos la infección con Gardnerella vaginalis se considera de transmisión sexual al ser más prevalente en las mujeres con actividad sexual y encontrarse con frecuencia en las parejas sexuales de las mujeres afectadas [5].

La vaginosis bacteriana es la alteración vaginal más frecuente en las mujeres en edad reproductiva y su incidencia varía dependiendo de la edad y el tipo de consulta. En la consulta ginecológica oscila entre el $10 \%$ y el 35\% [1], en las obstétricas entre el 4,9\% y el 50,9\% [3], en los servicios de infección de transmisión sexual entre el $20 \%$ y el $60 \%$ [5], en el tamizaje poblacional alrededor del $21 \%$ [6] y en adolescentes con actividad sexual alrededor del 45\% [7]. La prevalencia de la vaginosis bacteriana depende de la relación clínica, los factores sociodemográficos, los criterios de diagnóstico, la edad gestacional, entre otros [8].

El flujo vaginal de mal olor es el síntoma típico de la vaginosis bacteriana; sin embargo, más del $50 \%$ de los casos cursan asintomáticos y aproximadamente la mitad de las mujeres embarazadas que la padecen no relatan molestia vaginal en la consulta médica, por lo que pasa desapercibida [9]. En las embarazadas la vaginosis bacteriana es relevante debido a que aumenta el riesgo de complicaciones obstétricas, por ejemplo, la ruptura prematura de membranas y la corioamnionitis (infección del líquido amniótico), entre otras, y favorece el desarrollo de infecciones ascendentes en el canal vaginal, el útero y los anexos, que incrementan el riesgo de parto pretérmino hasta en un $60 \%$ [10] y, en consecuencia, las complicaciones y la mortalidad perinatal, elevando los costos de la atención en salud.

Los factores de riesgo para la vaginosis bacteriana aún son controvertidos; entre los más reportados en la literatura figuran los cambios hormonales, la presencia continua de semen en la vagina, las múltiples parejas sexuales, el uso frecuente de duchas vaginales, las infecciones del tracto urinario, la tricomoniasis, el hábito de fumar, las deficiencias de hierro, el estrés psicológico y el embarazo; condiciones que alteran el $\mathrm{pH}$ vaginal $[1,11]$. La fisiopatología de la vaginosis bacteriana está dada por los cambios en el pH vaginal, lo cual es aprovechado por los microorganismos para colonizar la vagina y provocar infecciones progresivas, generalmente asintomáticas $[12,13]$.

En pacientes fumadores se ha encontrado benzo(a)pireno diol epóxido en la secreción vaginal, que incrementa significativamente la inducción del fago de los lactobacilos, disminuye la producción de ácido láctico y peróxido de hidrógeno y facilita la instauración de microorganismos anaeróbicos [14]. Además, la vaginosis bacteriana es una condición que se agrava con el aumento de las infecciones de transmisión sexual por microorganismos como Neisseria gonorrhoeae, Chlamydia trachomatis, Trichomonas vaginalis, el virus del papiloma humano (PVH) y el virus de la inmunodeficiencia humana (VIH) [15]. 
Según la Encuesta Nacional de Salud de Colombia del 2010, una de cada cinco adolescentes ha estado alguna vez en embarazo [16]; situación que es compatible con las cifras reportadas en la ciudad de Medellín, donde 73,5 (por cada mil) mujeres entre los 15 y los 19 años se encontraban en estado de gestación para el año 2014 [17]. De igual manera, la mayor proporción de complicaciones del embarazo se presentó en las mujeres menores de 20 años; atribuidas a factores sociales, económicos, del comportamiento sexual y el estrés [18].

A pesar de estas implicaciones, aún no existen políticas definidas para el tamizaje y el tratamiento de la vaginosis bacteriana en las embarazadas, en parte, debido a la inconsistencia de los hallazgos de estudios clínicos sobre su etiología [19]. Algunos estudios realizados han evidenciado que factores estresantes acumulativos afectan la microbiota vaginal y al producto del embarazo a través de varias vías que se cruzan, entre las que se incluyen las neuroendocrinas, del comportamiento, las inmunológicas y las vasculares, que conducen al parto prematuro [20].

Considerando lo anterior, la vaginosis bacteriana se considera un problema complejo que causa una serie de molestias y complicaciones en las mujeres embarazadas, que merece atención clínica y epidemiológica en la perspectiva de la promoción de la salud y la prevención primaria y secundaria. El objetivo de esta investigación fue establecer la asociación de la vaginosis bacteriana con factores socioeconómicos, comportamiento sexual, higiene genital y estrés psicológico en embarazadas menores de 26 años de la ciudad de Medellín (Colombia), con el propósito de aportar conocimiento que oriente las intervenciones en salud sobre los factores de riesgo, la disminución de la vaginosis bacteriana y las complicaciones obstétricas; además, servir de insumo para otras investigaciones de tipo analítico que ayuden a clarificar los esquemas de tratamiento y lineamientos para la atención a embarazadas con vaginosis bacteriana asintomática y a repetición.

\section{Materiales y métodos}

\section{Tipo y población de estudio}

Se realizó un estudio de casos y controles, prospectivo, doble ciego, en gestantes menores de 26 años atendidas en el período de 2012 a 2014 en el control prenatal de la Red Pública de Salud, conformada por nueve instituciones prestadoras de servicios de salud (UPSS) que cubren todo el territorio del municipio de Medellín (Colombia).

En el programa Epi Info ${ }^{\mathrm{TM}}$ (Centers for Disease Control and Prevention, Atlanta, Giorgia, Estados Unidos), módulo Stalcal, se calculó el tamaño de la muestra bajo los parámetros: nivel de confianza del $95 \%$, potencia del $80 \%$, relación caso control $1: 1,3$, prevalencia del factor estudiado del $21,3 \%$ y razón de disparidad de 3,6 , para un total de 91 casos y 118 controles. 
Se definió como caso a la embarazada que cumpliera al menos con tres de los cinco criterios de diagnóstico para vaginosis bacteriana señalados por Amsel: a) aspecto del flujo blanco, grisáceo, adherente a la pared vaginal, b) presencia de células guía, células epiteliales tachonadas de cocobacilos Gram variables, con pérdida de la nitidez del borde celular, c) $\mathrm{pH}$ del flujo vaginal superior a 4,5, d) prueba de aminas positiva y e) relación ácido succínico/ácido láctico mayor de 0,5 [21]; además, no haber recibido tratamiento con clindamizina o metronidazol en los últimos 15 días ni con antibióticos de amplio espectro y no padecer enfermedades del sistema inmune (p. ej. VIH/Sida, diabetes gestacional, diabetes mellitus y desnutrición severa).

Los controles fueron tomados del mismo programa de control prenatal en cada UPSS, donde fueron seleccionadas aquellas embarazadas sin diagnóstico de vaginosis bacteriana y con edades entre cinco años por encima y cinco por debajo respecto a los casos que, al igual que estos, cumplieran con los requisitos de no consumo de medicamentos y no padecer enfermedades inmunológicas.

\section{Consideraciones éticas}

Una vez constatado que las gestantes cumplieran con los requisitos de inclusión, fueron informadas en un lugar privado sobre los objetivos y propósitos del proyecto de investigación y su participación en el mismo. Igualmente, se les explicó el consentimiento informado, aprobado previamente por el Comité de Bioética de Metrosalud, en el que se especificaban las condiciones a las que estarían sujetas al hacer parte o no de la investigación y, una vez verificada su comprensión, se procedió a la firma de este.

Esta investigación es clasificada como de riesgo mínimo según la Resolución 008430 de 1993 del Ministerio de Salud de Colombia, debido a que el análisis de flujo vaginal es un examen de rutina en la consulta prenatal y las complicaciones son mínimas bajo los protocolos estandarizados y por personal capacitado, tal como sucedió en esta investigación. Toda la información recolectada se salvaguardó en el archivo del Grupo de Investigación de Salud Sexual y Cáncer de la Escuela de Microbiología de la Universidad de Antioquia.

\section{Recolección de datos}

Inmediatamente después, se aplicó la encuesta que incluía preguntas sociodemográficas, ginecoobstétricas, del comportamiento sexual y hábitos higiénicos y la Escala de Reajuste Social de Holmes y Rahe utilizada para medir la magnitud de estrés que experimenta una persona durante un tiempo, generalmente en los últimos seis meses [22]. Dicha escala de estrés propuesta por Holmes y Rahe en 1968 fue validada por Bruner en 1994 [23] y por Acuña en 2012 [24] en sujetos de la población mexicana, sin cambios significativos entre estas. Esta escala eva- 
lúa 49 eventos estresantes que anteceden a una enfermedad o situación de salud sobre un máximo de 1.690 puntos, categorizados en cuatro niveles: a) sin estrés: menos de 100 puntos, b) estrés bajo: entre 100 y 415 puntos, c) estrés medio: entre 416 y 830 puntos y d) estrés alto: mayor que 830 puntos.

\section{Recolección de muestras}

Las participantes fueron citadas inmediatamente para la toma de las muestras del flujo vaginal. Se recolectó una primera muestra del fondo del saco posterior y de los laterales de la vagina, que se extendió uniforme y circularmente cubriendo un área de $1,5 \mathrm{~cm}$ de diámetro en un extremo de la lámina portaobjetos. Luego se complementó con una muestra del canal endocervical que se extendió circularmente en el centro del mismo portaobjetos, el cual se procesó para la coloración de Gram.

Se tomó una segunda muestra vaginal con aplicador que se introdujo en un tubo de ensayo con $2 \mathrm{~mL}$ de solución salina estéril, la cual se empleó para el examen en fresco. La lectura e interpretación del Gram y el Fresco fue realizada por bacteriólogos del Laboratorio Docente Asistencial e Investigativo de la Escuela de Microbiología de la Universidad de Antioquia. La medición del $\mathrm{pH}$ y el test de aminas se efectuaron en el momento de la toma de la muestra.

Las gestantes que cumplieron con los criterios de inclusión y fueron positivas para vaginosis bacteriana fueron clasificadas como casos y las negativas como controles. Todos los casos fueron remitidos nuevamente a control prenatal para su tratamiento, al igual que aquellos controles que fueron positivos para otras infecciones cervicovaginales.

\section{Análisis estadístico}

El análisis de la información se realizó con el programa SPSS versión 21 (IBM, Nueva York, Estados Unidos) a partir de una base de datos en Microsoft Excel 7.0 que contenía los datos de las encuestas y los resultados microbiológicos. Inicialmente, se compararon las frecuencias y las medias de los valores de las variables para observar las diferencias entre los casos y los controles, y se calcularon las razones de disparidad crudas y ajustadas; estas últimas mediante regresión logística por el método paso a paso hacia delante (Forward Wald) para un nivel de significancia $p<0,05$, a fin de encontrar las variables que mejor explicaran el desenlace, o sea, la vaginosis bacteriana.

\section{Resultados}

\section{Características sociodemográficas de los casos y controles}

La disponibilidad mínima del dato por variable (total de respuestas/total de participantes) fue del 80,5\%. En el estudio participaron 217 embarazadas menores de 26 años, distribuidas en 90 casos y 127 controles, con edades promedio de 19,8 y 
20,1 años, respectivamente $(p=0,079)$. La edad gestacional promedio de los casos fue de tres semanas menos respecto a la de los controles $(24,7$ frente a 27,8 ; $p=0,314)$. Según el trimestre de embarazo el $51,7 \%$ de los casos se encontraban en el segundo y el $57,7 \%$ de los controles en el tercero (véase tabla 1 ).

\begin{tabular}{|c|c|c|c|c|c|c|}
\hline \multicolumn{2}{|l|}{ Características } & \multicolumn{2}{|c|}{ Casos $(n=90)$} & \multicolumn{2}{|c|}{ Controles $(n=127)$} & Valor $\mathrm{T}$ \\
\hline \multicolumn{2}{|l|}{ Edad (años) } & \multicolumn{2}{|c|}{$19,8 \pm 3,1$} & \multicolumn{2}{|c|}{$20,1 \pm 2,8$} & 0,079 \\
\hline \multicolumn{2}{|c|}{ Edad inicio relaciones sexuales (años) } & \multicolumn{2}{|c|}{$15,2 \pm 2,1$} & \multicolumn{2}{|c|}{$15,7 \pm 2,3$} & 0,432 \\
\hline \multicolumn{2}{|c|}{ Edad gestacional (semanas) } & \multicolumn{2}{|c|}{$24,7 \pm 8,8$} & \multicolumn{2}{|c|}{$27,8 \pm 7,9$} & 0,314 \\
\hline \multicolumn{2}{|l|}{ Escolaridad (años) } & \multicolumn{2}{|c|}{$9,6 \pm 2,8$} & \multicolumn{2}{|c|}{$9,6 \pm 2,9$} & 0,694 \\
\hline \multirow{2}{*}{\multicolumn{2}{|c|}{ Nivel estrés según escala }} & \multicolumn{2}{|c|}{$242,2 \pm 112,2$} & \multicolumn{2}{|c|}{$276,7 \pm 150,9$} & 0,002 \\
\hline & & $\mathrm{n}$ & $\%$ & $\mathrm{n}$ & $\%$ & Valor $p$ \\
\hline \multirow[t]{4}{*}{ Régimen de salud } & Contributivo & 4 & 4,4 & 9 & 7,1 & \multirow[t]{4}{*}{0,668} \\
\hline & Subsidiado & 72 & 80,0 & 98 & 79,0 & \\
\hline & Vinculado & 14 & 115,6 & 17 & 13,7 & \\
\hline & No Responde & 0 & 0 & 3 & - & \\
\hline \multirow[t]{4}{*}{ Edad gestacional } & Primer trimestre & 9 & 10,1 & 5 & 4,1 & \multirow[t]{4}{*}{0,668} \\
\hline & Segundo trimestre & 46 & 51,7 & 47 & 38,5 & \\
\hline & Tercer trimestre & 34 & 38,2 & 70 & 57,7 & \\
\hline & Sin dato & 1 & - & 5 & - & \\
\hline Primer embarazo & Sí & 57 & 64,8 & 76 & 59,8 & 0,0463 \\
\hline Antecedente aborto & Sí & 14 & 15,7 & 20 & 16,1 & 0,0938 \\
\hline \multirow[t]{4}{*}{ Ocupación } & Estudiante & 23 & 25,8 & 31 & 24,4 & \multirow[t]{4}{*}{0,668} \\
\hline & Ama de casa & 62 & 69,7 & 80 & 63,0 & \\
\hline & Obrera & 4 & 4,5 & 10 & 7,9 & \\
\hline & Desempleada & 0 & 0 & 6 & 4,8 & \\
\hline \multirow[t]{5}{*}{ Estado civil } & Soltera & 41 & 45,6 & 58 & 46 & \multirow[t]{5}{*}{0,501} \\
\hline & Unión Libre & 45 & 50 & 60 & 48,4 & \\
\hline & Casada & 3 & 3,3 & 7 & 5,0 & \\
\hline & Divorciada & 1 & 1,1 & 0 & 0 & \\
\hline & Sin dato & 0 & 0 & 1 & - & \\
\hline \multirow{3}{*}{$\begin{array}{l}\text { Dependencia } \\
\text { económica }\end{array}$} & Ella misma & 2 & 2,2 & 11 & 8,7 & \multirow[t]{3}{*}{0,085} \\
\hline & Pareja/esposo & 41 & 45,6 & 48 & 37,8 & \\
\hline & Otras personas & 47 & 52,2 & 68 & 53,5 & \\
\hline
\end{tabular}

La distribución de las características sociodemográficas fue similar entre los casos y los controles en cuanto a la edad, la escolaridad, la pertenencia al régimen de seguridad social, la ocupación, el estado civil y la dependencia económica; por consiguiente, no se obtuvieron diferencias estadísticamente significativas, al igual que para los antecedentes ginecoobstétricos (abortos, paridad y semanas de ges- 
tación). Se destaca el alto porcentaje de embarazadas primigestantes en los casos $(64,8 \%)$ y los controles $(59,8 \%)$ (véase tabla 1$)$.

\section{Factores de riesgo para vaginosis bacteriana}

La frecuencia de los factores de riesgo del comportamiento sexual y los hábitos higiénicos para vaginosis bacteriana en los casos fue mayor respecto a los controles en cuanto al inicio de las relaciones sexuales antes de los 15 años de edad (32,2\% frente a $25,4 \%)$, las relaciones coitales durante el embarazo $(67,7 \%$ frente a $60,6 \%)$, las relaciones sexuales frecuentes $(10,0 \%$ frente a $5,5 \%)$, el consumo de tabaco $(5,8 \%$ frente a $4,0 \%)$, el aseo vaginal diario $(98,9 \%$ frente a $96,0 \%)$, el aseo vaginal con productos comerciales $(24,3 \%$ frente a $15,6 \%)$, las duchas vaginales $(15,6 \%$ frente a $13,4 \%)$ y el uso de tampones $(28,9 \%$ frente a $27,6 \%)$ (véase tabla 2).

\begin{tabular}{|c|c|c|c|c|c|}
\hline \multirow[t]{2}{*}{ Características } & \multicolumn{2}{|c|}{ Casos $(n=90)$} & \multicolumn{2}{|c|}{ Controles $(n=126)$} & \multirow[t]{2}{*}{ Valor $p$} \\
\hline & $n$ & $\%$ & $\mathrm{n}$ & $\%$ & \\
\hline $\begin{array}{l}\text { Inicio de las relaciones sexuales antes } \\
\text { de los } 15 \text { años de edad }\end{array}$ & 29 & 32,2 & 32 & 25,4 & 0,34 \\
\hline $\begin{array}{l}\text { Relaciones sexuales durante el emba- } \\
\text { razo }\end{array}$ & 60 & 67,4 & 77 & 60,6 & 0,49 \\
\hline $\begin{array}{l}\text { Relaciones sexuales diarias y día por } \\
\text { medio }\end{array}$ & 9 & 10,0 & 7 & 5,5 & 0,50 \\
\hline $\begin{array}{l}\text { Dos o más parejas sexuales en los últi- } \\
\text { mos seis meses }\end{array}$ & 20 & 17,0 & 26 & 21,0 & 0,87 \\
\hline No uso de condón & 52 & 57,8 & 86 & 67,7 & 0,15 \\
\hline $\begin{array}{l}\text { Historia de uso de anticonceptivos } \\
\text { hormonales }\end{array}$ & 38 & 42,2 & 56 & 44,1 & 0,85 \\
\hline Antecedentes de aborto & 14 & 15,7 & 20 & 16,1 & 0,09 \\
\hline $\begin{array}{l}\text { Antecedente de infección de transmisión } \\
\text { sexual }\end{array}$ & 10 & 11,4 & 9 & 7,3 & 0,32 \\
\hline Consumo de cigarrillo (tabaco) & 5 & 5,8 & 5 & 4,0 & 0,55 \\
\hline Aseo vaginal diario & 89 & 98,9 & 121 & 96,0 & 0,40 \\
\hline Aseo vaginal con agua y jabón & 52 & 57,8 & 89 & 71,0 & 0,07 \\
\hline Aseo vaginal con productos comerciales & 22 & 24,3 & 22 & 17,2 & 0,28 \\
\hline Duchas vaginales & 14 & 15,6 & 16 & 13,4 & 0,69 \\
\hline Uso de protectores diarios & 59 & 65,6 & 85 & 67,7 & 0,88 \\
\hline Uso de tampones antes del embarazo & 26 & 28,9 & 34 & 27,6 & 0,88 \\
\hline
\end{tabular}

En cuanto a los demás factores de riesgo (historia de dos o más parejas sexuales en los últimos seis meses, el no uso del condón, los antecedentes del uso de anticonceptivos hormonales, el aseo vaginal con agua y jabón y el uso de protectores diarios) se encontró mayor frecuencia en los controles que en los casos. Ninguno 
de los factores de riesgo evaluados se asociaron a la vaginosis bacteriana en el análisis bivariado (véase tabla 2); sin embargo, se resalta la susceptibilidad de las embarazadas para contraer infecciones de transmisión sexual ante la alta frecuencia de los factores como inicio de las relaciones sexuales ante de los 15 años de edad, la actividad sexual, la historia de dos o más parejas durante el embarazo y el no uso del condón.

\section{Nivel de estrés psicológico}

En cuanto al nivel de estrés se encontró que fue mayor en los controles que en los casos, con valores promedio de 276,7 y 242,2 puntos, respectivamente, correspondientes en ambos casos a estrés bajo $(p=0,002)$ (véase figura 1$)$. En los casos predominó el nivel de estrés bajo y en los controles el intermedio. En el 9,4\% de los casos y el $11,9 \%$ de los controles no se presentó estrés y ninguna embarazada presentó estrés severo.

\section{Signos y síntomas percibidos por las embarazadas}

La presencia de flujo vaginal, prurito, ardor, dispareunia y dolor pélvico no se asociaron a vaginosis bacteriana ni presentaron diferencias estadísticamente significativas en los casos respecto a los controles, a excepción del sangrado poscoital que fue tres veces mayor en los primeros respecto a los segundos $(p=0,036)$ (véase tabla 3 ).

\begin{tabular}{|c|c|c|c|c|c|}
\hline \multirow[t]{2}{*}{ Características } & \multicolumn{2}{|c|}{ Casos $(n=90)$} & \multicolumn{2}{|c|}{ Controles $(n=126)$} & \multirow[t]{2}{*}{ Valor $p$} \\
\hline & $\mathrm{n}$ & $\%$ & $\mathrm{n}$ & $\%$ & \\
\hline Flujo vaginal & 50 & 55,6 & 72 & 56,7 & 0,489 \\
\hline Prurito & 27 & 30,0 & 40 & 31,5 & 0,467 \\
\hline Ardor & 16 & 17,8 & 22 & 17,3 & 0,535 \\
\hline Dispareunia & 14 & 15,6 & 22 & 17,3 & 0,439 \\
\hline Sangrado postcoital & 9 & 10,0 & 4 & 3,1 & 0,036 \\
\hline Dolor pélvico & 20 & 22,2 & 30 & 23,6 & 0,471 \\
\hline
\end{tabular}

\section{Hallazgos microbiológicos}

En el $90,0 \%$ de los casos se identificaron células guía, en el 20\% Mobiluncus spp. y en el 4,4\% lactobacilos; estos últimos con predominio de cantidad escasa en el 3,3\% y moderada en el $1,1 \%$. En los controles, en el $82,7 \%$ se detectaron lactobacilos, con predominio de cantidad abundante en el $68,5 \%$, y en el $1,6 \%$ se encontraron células guía. La candidiasis fue más frecuente en los controles $(28,3 \%)$ que en los casos $(4,4 \%)$, por lo que en consecuencia se observó una razón de disparidad menor que 1 (razón de disparidad: 0,118; intervalo de confianza del 95\%: 0,040-0,033; $\left.\mathrm{Chi}^{2}=23,247, p=0,000\right)$. La frecuencia de tricomoniasis fue baja y similar en ambos grupos, $1,1 \%$ en los casos y $1,6 \%$ en los controles (razón de disparidad: 0,702 ; intervalo de confianza del 95\%: 0,063-7,864; $\left.\mathrm{Chi}^{2}=0,085, p=0,627\right)$. 
Finalmente, luego de explorar varios modelos en la regresión logística, la vaginosis bacteriana en las embarazadas se relacionó de forma inversamente proporcional con la candidiasis (razón de disparidad:10,9; intervalo de confianza del 95\%: 3,138,5), el trimestre del embarazo (razón de disparidad: 0,51; intervalo de confianza del 95\%: 0,30-0,85) y la edad de inicio de las relaciones sexuales (razón de disparidad: 0,83; intervalo de confianza del 95\%: 0,70-0,97); los dos últimos con coeficientes negativos y razones de disparidad menores a uno. Luego de ajustar el modelo por edad, el estrés y la presencia de tricomoniasis también se asociaron a la vaginosis bacteriana (véase tabla 4). En este sentido, el modelo explicó la clasificación correcta del $73,8 \%$ de los controles, el $64,2 \%$ de los casos y el $69,6 \%$ del total de participantes. Estos factores solo explican en un $22,0 \%\left(R^{2}\right.$ de Nagelkerke: $0,22)$ el comportamiento de la vaginosis bacteriana en las embarazadas.

\begin{tabular}{|c|c|c|c|c|c|c|c|c|c|}
\hline \multicolumn{2}{|c|}{$\begin{array}{l}\text { Pasos en } \\
\text { la regresión }\end{array}$} & \multirow{2}{*}{$\begin{array}{l}\text { Coeficiente } \\
\text { logístico }\end{array}$} & \multirow{2}{*}{$\begin{array}{l}\begin{array}{l}\text { Error } \\
\text { estándar }\end{array} \\
0,628\end{array}$} & \multirow{2}{*}{$\begin{array}{l}\text { Estadístico } \\
\text { de Wald } \\
13,671\end{array}$} & \multirow{2}{*}{ 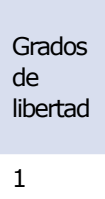 } & \multirow{2}{*}{$\begin{array}{l}\text { Valor } p \\
0,000\end{array}$} & \multirow{2}{*}{$\begin{array}{l}\begin{array}{l}\text { Razón de } \\
\text { disparidad } \\
\text { Inferior }\end{array} \\
10,189\end{array}$} & \multicolumn{2}{|c|}{$\begin{array}{l}\text { Intervalo } \\
\text { de confianza } \\
\text { del } 95 \% \\
\text { Superior }\end{array}$} \\
\hline \multirow[t]{2}{*}{ Paso 1} & Candidiasis & & & & & & & 2,977 & 34,87 \\
\hline & Constante & $-4,590$ & 1,224 & 14,068 & 1 & 0,000 & 0,010 & & \\
\hline \multirow[t]{3}{*}{ Paso 2} & $\begin{array}{l}\text { Trimestre } \\
\text { de embarazo }\end{array}$ & $-0,603$ & 0,258 & 5,474 & 1 & 0,019 & 0,547 & 0,330 & 0,907 \\
\hline & Candidiasis & 2,342 & 0,632 & 13,717 & 1 & 0,000 & 10,402 & 3,012 & 35,923 \\
\hline & Constante & $-3,187$ & 1,351 & 5,566 & 1 & 0,018 & 0,041 & & \\
\hline \multirow[t]{4}{*}{ Paso 3} & $\begin{array}{l}\text { Edad de } \\
\text { inicio de } \\
\text { relaciones } \\
\text { sexuales }\end{array}$ & $-0,184$ & 0,082 & 5,035 & 1 & ,025 & 0,832 & 0,708 & 0,977 \\
\hline & $\begin{array}{l}\text { Trimestre } \\
\text { de embarazo }\end{array}$ & $-0,671$ & 0,262 & 6,548 & 1 & ,010 & 0,511 & 0,306 & 0,855 \\
\hline & Candidiasis & 2,394 & 0,642 & 13,913 & 1 & 0,000 & 10,961 & 3,115 & 38,567 \\
\hline & Constante & $-0,271$ & 1,862 & 0,021 & 1 & 0,884 & 0,763 & & \\
\hline
\end{tabular}

\section{Discusión}

Las teorías establecidas en la fisiopatología de la vaginosis bacteriana y el sinergismo microbiológico aún no están dilucidadas; además de la variación del pH parece haber una disminución de los efectos restrictivos de la microbiota normal, al disminuir notablemente los lactobacilos y propiciar la proliferación masiva de los anaerobios y Gardnerella vaginalis [1, 3, 21].

En esta investigación, para el diagnóstico de vaginosis bacteriana, se tuvieron en cuenta tres de los cinco criterios Amsel [21]. Dadhwal y colaboradores (2010) [25] simplificaron el diagnóstico a dos criterios, $\mathrm{pH}$ vaginal y prueba de aminas 
positivas, para los lugares geográficos donde la microscopía o la tinción de Gram no está disponible, con una sensibilidad del 51,2\%, especificidad del $98 \%$, valor predictivo positivo del $71 \%$ y valor predictivo negativo del $95,5 \%$. Estos nuevos criterios fueron tomados por Vera y colaboradores (2009) [26] como prueba estándar para validar el Sistema de Puntuación de Nugent para diagnóstico de vaginosis bacteriana en mujeres embarazadas, reportando una sensibilidad del $100 \%$, especificidad del $96,4 \%$, valor predictivo positivo del $82,3 \%$ y valor predictivo negativo del $100 \%$.

La prevalencia de la vaginosis bacteriana en los estudios transversales y longitudinales realizados en hospitales de maternidad puede variar: en Dinamarca, en mujeres en el segundo trimestre de embarazo, se han reportado cifras que alcanzan el 16,0\% [27], en Maiduguri, noreste de Nigeria, se ha encontrado en el $17,3 \%$ de las embarazadas con flujo anormal [28], en Río de Janeiro, Brasil, en el 28,1\% de embarazadas asintomáticas [29], en Mwanza, Tanzania, en el 28,5\% [30] y en Jartum, Sudán, en el 49,8\% [31] de las embarazadas. En el presente estudio de casos y controles la prevalencia fue del $41,4 \%$.

La vaginosis bacteriana tiende a ser más frecuente en el segundo y tercer trimestre del embarazo. Para este estudio, la mitad de los casos se encontraban en el segundo trimestre; siendo inferior a la frecuencia reportado por Cammack y colaboradores (2011) [32] en el mismo trimestre de embarazo (51,7\% frente a $77,0 \%)$.

\section{Vaginosis bacteriana y factores de riesgo}

La literatura médica ha reportado como factores de riesgo para la vaginosis bacteriana la alta frecuencia de relaciones sexuales, el cambio de parejas sexuales, el no uso del condón, la higiene genital inadecuada, el uso frecuente de protectores diarios, el estrés psicológico, el consumo de tabaco, el analfabetismo y el desempleo [33, 34], entre otros; sin embargo, el comportamiento de estos no ha sido consistente.

Por otra parte, los diseños analíticos que tienden a probar la causalidad y que sean particularmente de tipo casos y controles son escasos; en su mayoría, las asociaciones están basadas en diseños descriptivos o de corte transversal que muestran su significancia estadística. Otros estudios, con resultados más acordes a los de esta investigación, no encontraron asociación de la vaginosis bacteriana con la mayor frecuencia de duchas vaginales, el uso de productos vaginales, la frecuencia del coito, el mayor número de parejas sexuales, los antecedentes de infecciones de transmisión sexual, los niveles socioeconómicos y de escolaridad bajos; tampoco con el apoyo social, la ansiedad, el estrés y los antecedentes de tabaquismo antes o durante el embarazo $[8,33,34]$.

En este estudio, el modelo que mejor explicó la vaginosis bacteriana en embarazadas estuvo dado por la menor frecuencia de candidiasis en los casos, el segundo 
trimestre del embarazo y la edad de inicio de las relaciones sexuales antes de los 15 años. Luego de ajustar el modelo por la edad, el nivel de estrés psicológico y la infección por tricomonas también se asociaron a la vaginosis bacteriana, lo cual indica que amerita continuar profundizando en la causalidad de la vaginosis bacteriana a través de diseños controlados.

\section{Vaginosis bacteriana y estrés}

El estrés psicológico es considerado un factor de riesgo potencial de vaginosis bacteriana, causa biológica plausible. Estudios en animales y humanos muestran que el estrés psicosocial impacta en la función inmune y endocrina, y aumenta la susceptibilidad a la infección. La evidencia específica en el embarazo es más limitada y algunos estudios asocian los niveles altos de estrés psicosocial con niveles elevados de citoquinas proinflamatorias y cortisol en las embarazadas. Los factores estresantes de carácter socioeconómico también se han asociado consistentemente con la vaginosis bacteriana [33].

El estrés es cada vez más reconocido como un factor de riesgo del parto prematuro y se ha postulado que la infección o las alteraciones inmunológicas pueden mediar esta asociación [32]. Culhane y colaboradores (2001) [13], tras evaluar varios factores de riesgo sociodemográficos y el estrés percibido, asociaron a la vaginosis bacteriana con el factor estresante «comunidad de personas sin hogar» (razón de disparidad: 6,7; intervalo de confianza del 95\%: 1,6-27,8), lo cual llevó a la conclusión de que factores estresantes individuales y comunitarios son determinantes en la vaginosis bacteriana. Paul y colaboradores (2008) [33] encontraron esta asociación con un mayor número de acontecimientos estresantes; sin embargo, no se asoció a la vaginosis bacteriana con el estrés valorado en la escala de reajuste social de Holmes y Rahe, escala que se encuentra validada para medir el estrés en embarazadas [23, 24].

\section{Vaginosis bacteriana y complicaciones}

Esta investigación no tenía por objetivo estudiar la relación de la vaginosis bacteriana con las complicaciones del embarazo como la corioamnionitis, el parto pretérmino y el bajo peso al nacer; sin embargo, es importante resaltar la importancia de la vaginosis bacteriana en la morbilidad y mortalidad perinatal, que se ha establecido a partir de varios estudios que la reportan como un factor de riesgo para estas complicaciones [27, 35].

El estudio realizado por Mancuso y colaboradores (2011) [36] describe un posible mecanismo entre la infección genital asintomática y el parto pretérmino mediante la estimulación de la liberación de prostaglandina bacteriana o endotoxina bacteriana que se introduce en el líquido amniótico y lleva a la liberación de citoquinas y al trabajo de parto espontáneo. 


\section{Vaginosis bacteriana, signos y síntomas}

En este estudio no se encontró relación entre la vaginosis bacteriana y los signos y síntomas percibidos por las embarazadas, excepto el sangrado poscoital; sin embargo, se encontró una alta frecuencia de flujo vaginal que supera la descrita por Ibrahim y colaboradores (2014) [28] (55,6\% frente a 17,3\%).

\section{Perspectivas y limitaciones}

Los resultados obtenidos en esta investigación aportan pautas para los programas de tamizaje y protocolos de atención a embarazadas con vaginosis bacteriana y a la evaluación de técnicas diagnósticas presuntivas; útiles para la racionalización de los recursos existentes. Se resalta el diseño epidemiológico de casos y controles, estudio analítico que se aproxima más a la causalidad en comparación con los descriptivos; sin embargo, la escasez de este tipo de estudios limitó la comparación de este trabajo con estudios similares de manera que se pudieran contrastar los hallazgos frente a los factores de riesgo no concordantes. En este sentido, el hecho de no encontrar asociaciones con la mayor parte de los factores en estudio puede deberse a la similitud social, cultural, económica y de acceso a los servicios de salud de los casos y los controles, lo cual también está a favor de la consistencia interna del trabajo, en el control de sesgos. Se sugiere, para próximas investigaciones realizar estudios de cohorte que permitan avanzar en la causalidad de la vaginosis bacteriana.

\section{Conclusiones}

La vaginosis bacteriana se encontró asociada estadísticamente a la ausencia de candidiasis, al segundo trimestre del embarazo, la edad de inicio de las relaciones sexuales antes de los 15 años y, después de ajustar el modelo por la edad, al nivel de estrés y la tricomoniasis. El comportamiento de los factores de riesgo inherentes a las prácticas sexuales e higiene genital no mostró diferencias entre los casos y los controles; sin embargo, se destaca su alta frecuencia, lo que puede alterar el microambiente vaginal. El nivel de estrés psicológico fue mayor en los controles.

\section{Agradecimientos}

Esta investigación fue financiada con recursos en especie del Grupo de Investigación de Salud Sexual y Cáncer, Escuela de Microbiología, Universidad de Antioquia, y Metrosalud.

Agradecemos tanto a Metrosalud como al Laboratorio Docente Asistencial de la Escuela de Microbiología, Universidad de Antioquia, por el apoyo en el desarrollo de esta investigación. 


\section{Bibliografía}

1. Georgijevic A, Cjukic-Ivancevic S, Bujko M. [Bacterial vaginosis. Epidemiology and risk factors]. Srp Arh Celok Lek 2000; 128: 29-33.

2. Waters TP, Denney JM, Mathew L, Goldenberg RL, Culhane JF. Longitudinal trajectory of bacterial vaginosis during pregnancy. Am J Obstet Gynecol 2008; 199: 431 e431435.

3. Morris M, Nicoll A, Simms I, Wilson J, Catchpole M. Bacterial vaginosis: a public health review. BJOG 2001; 108: 439-450.

4. Ness RB, Hillier SL, Richter HE, Soper DE, Stamm C, McGregor J, et al. Douching in relation to bacterial vaginosis, lactobacilli, and facultative bacteria in the vagina. Obstet Gynecol 2002; 100: 765.

5. Brotman RM. Vaginal microbiome and sexually transmitted infections: an epidemiologic perspective. J Clin Invest 2011; 121: 46104617.

6. Villa M, Escobar S, Tamayo L, Valencia M, Vasquez ME, Lopera M. Caracterización de la Vaginosis bacteriana y factores de riesgo asociados en mujeres de 14-65 años de zona minera de Amagá, Antioquia. Rev Epidemiol de Ant 1999; 25: 325-331.

7. Tamayo-Acevedo LS, López MI, Villegas A, Agudelo C, Arrubla M, Muñoz-Tamayo J. Determinantes de salud sexual e ITS en adolescentes rurales, escolarizados, Medellín, Colombia, 2008. Rev Salud Pública Medellín 2011; 5: 7-24

8. Trabert B, Misra DP. Risk factors for bacterial vaginosis during pregnancy among African American women. Am J Obstet Gynecol 2007; 197: 477 e471-478.

9. Vogel I, Thorsen $\mathbf{P}$, Jeune B, Jacobsson B, Ebbesen N, Arpi M, et al. Acquisition and elimination of bacterial vaginosis during pregnancy: a Danish population-based study. Infect Dis Obstet Gynecol 2006; 2006: 94646.

10. Tebes CC, Lynch C, Sinnott J. The effect of treating bacterial vaginosis on preterm labor. Infect Dis Obstet Gynecol 2003; 11: 123-129.

11. Fonck K, Kaul R, Keli F, Bwayo JJ, Ngugi EN, Moses S, et al. Sexually transmitted infections and vaginal douching in a population of female sex workers in Nairobi, Kenya. Sex Transm Infect 2001; 77: 271-275.

12. Kent HL. Epidemiology of vaginitis. Am J Obstet Gynecol 1991; 165: 1168-1176.

13. Culhane JF, Rauh V, McCollum KF, Hogan VK, Agnew K, Wadhwa PD. Maternal stress is associated with bacterial vaginosis in hu- man pregnancy. Matern Child Health J 2001; 5: $127-134$

14. Pavlova SI, Tao L. Induction of vaginal Lactobacillus phages by the cigarette smoke chemical benzo[a]pyrene diol epoxide. Mutat Res 2000; 466: 57-62.

15. Morris MC, Rogers PA, Kinghorn GR. Is bacterial vaginosis a sexually transmitted infection? Sex Transm Infect 2001; 77: 63-68.

16. República de Colombia, Ministerio de la Protección Social, Asociación Probienestar de la Familia Colombiana-Profamilia, Bienestar Familiar, Agencia de Estados Unidos para el Desarrollo Internacional (USAID). 2011. Encuesta Nacional de Demografía y Salud, 2010. http://profamilia.org. co/docs/ENDS\%202010.pdf, accessed febrero 2016.

17. República de Colombia, Gobernación de Antioquia, Secretaria Seccional de Salud y Protección Social de Antioquia. 2015. Indicadores de Natalidad: tasas de fecundidad según grupos de edad y municipio de residencia habitual de la madre. Subregión Valle de Aburrá, 2014. http://diagnosticosalud. dssa.gov.co/indicadores-basicos-de-saludpor-subregion-y-municipio/valle-de-aburra/ indicadores-de-natalidad-valleaburra/, accessed febrero 2016

18. República de Colombia, Alcaldía de Medellín, Secretaría de Salud de Medellín. 2014. Indicadores Básicos: Situación de Salud en Medellín. https://www.medellin.gov. $\mathrm{co} / \mathrm{irj} / \mathrm{go} / \mathrm{km} /$ docs/pccdesign/SubportaldelCiudadano_2/PlandeDesarrollo_0_19/IndicadoresyEstadsticas/Shared\%20Content/Libros $\% 20$ de $\% 20$ indicadores/Indicadores $\% 20$ Basicos\%202014.pdf, accessed febrero 2016.

19. Rauh VA, Culhane JF, Hogan VK. Bacterial vaginosis: a public health problem for women. J Am Med Womens Assoc 2000; 55: 220224.

20. Rich-Edwards JW, Grizzard TA. Psychosocial stress and neuroendocrine mechanisms in preterm delivery. Am J Obstet Gynecol 2005; 192: S30-35.

21. Amsel R, Totten PA, Spiegel CA, Chen KC, Eschenbach D, Holmes KK. Nonspecific vaginitis. Diagnostic criteria and microbial and epidemiologic associations. Am J Med 1983; 74: 14-22.

22. Holmes TH, Rahe RH. The Social Readjustment Rating Scale. J Psychosom Res 1967; 11: $213-218$

23. Bruner CA, Acuña $L$, Gallardo LM, Atri $\mathbf{R}$, Hernández A, Rodríguez $\mathbf{W}$, et al. La es- 
cala de reajuste social (SRRS) de Holmes y Rahe en México. Rev Latinoam Psicol 1994; 26: 253-269.

24. Acuña L, González-García DA, Bruner CA. La escala de reajuste social de Holmes y Rahe en México: Una revisión después de 16 años. Rev Mex Psicología 2012; 29: 16-32.

25. Dadhwal V, Hariprasad R, Mittal S, Kapil A. Prevalence of bacterial vaginosis in pregnant women and predictive value of clinical diagnosis. Arch Gynecol Obstet 2010; 281: 101-104.

26. Vera LM, López N, Arámbula AL. Validez y reproducibilidad del sistema de puntuación de Nugent para el diagnóstico de vaginosis bacteriana en mujeres embarazadas. Rev Chil Obstet Ginecol 2009; 74: 286-291.

27. Svare JA, Schmidt $H$, Hansen BB, Lose G. Bacterial vaginosis in a cohort of Danish pregnant women: prevalence and relationship with preterm delivery, low birthweight and perinatal infections. BJOG 2006; 113: 1419-1425.

28. Ibrahim SM, Bukar M, Galadima GB, Audu BM, Ibrahim HA. Prevalence of bacterial vaginosis in pregnant women in Maiduguri, North-Eastern Nigeria. Niger J Clin Pract 2014; 17: 154-158.

29. Krauss-Silva L, Almada-Horta A, Alves MB, Camacho KG, Moreira ME, Braga A. Basic vaginal $\mathrm{pH}$, bacterial vaginosis and aerobic vaginitis: prevalence in early pregnancy and risk of spontaneous preterm delivery, a prospective study in a low socioeconomic and multiethnic South American population. BMC Pregnancy Childbirth 2014; 14: 107.
30. Shayo PA, Kihunrwa A, Massinde AN, Mirambo $M$, Rumanyika $R$, Ngwalida $N$, et al. Prevalence of bacterial vaginosis and associated factors among pregnant women attending at Bugando Medical Centre, Mwanza, Tanzania. Tanzan J Health Res 2012; 14: 175182.

31. Abdelaziz ZA, Ibrahim ME, Bilal NE, Hamid ME. Vaginal infections among pregnant women at Omdurman Maternity Hospital in Khartoum, Sudan. J Infect Dev Ctries 2014; 8: 490-497.

32. Cammack AL, Buss $C$, Entringer S, Hogue CJ, Hobel CJ, Wadhwa PD. The association between early life adversity and bacterial vaginosis during pregnancy. Am J Obstet Gynecol 2011; 204: 431 e431-438.

33. Paul K, Boutain D, Manhart L, Hitti J. Racial disparity in bacterial vaginosis: the role of socioeconomic status, psychosocial stress, and neighborhood characteristics, and possible implications for preterm birth. Soc Sci Med 2008; 67: 824-833.

34. Simhan HN, Bodnar LM, Krohn MA. Paternal race and bacterial vaginosis during the first trimester of pregnancy. Am J Obstet Gynecol 2008; 198: 196 e191-194.

35. Hillier SL, Nugent RP, Eschenbach DA, Krohn MA, Gibbs RS, Martin DH, et al. Association between bacterial vaginosis and preterm delivery of a low-birth-weight infant. The Vaginal Infections and Prematurity Study Group. N Engl J Med 1995; 333: 1737-1742.

36. Mancuso MS, Figueroa D, Szychowski JM, Paden MM, Owen J. Midtrimester bacterial vaginosis and cervical length in women at risk for preterm birth. Am J Obstet Gynecol 2011; 204: 342 e341-345. 
